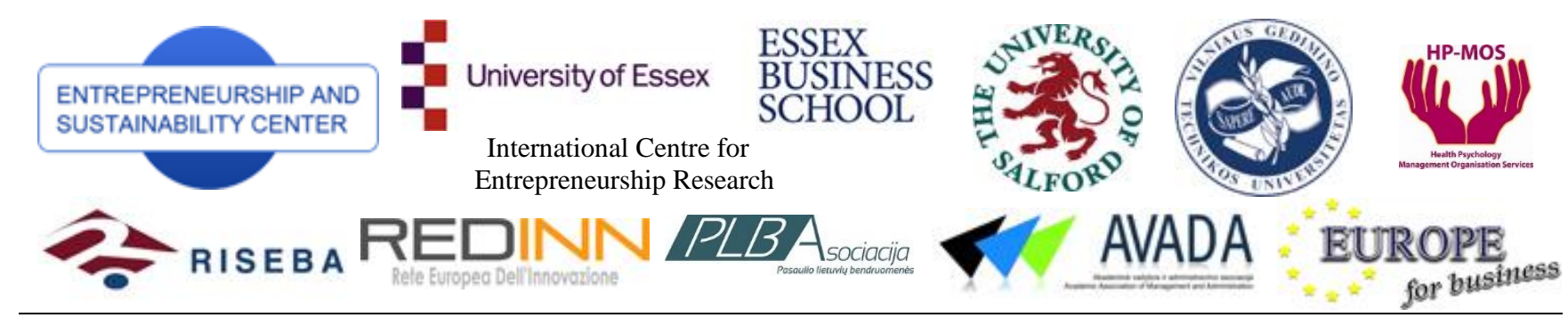

ENTREPRENEURSHIP AND SUSTAINABILITY ISSUES

ISSN 2345-0282 (online) http://jssidoi.org/jesi/aims-and-scope-of-research/

\title{
SUSTAINABLE ENERGY ENTREPRENEURSHIP THROUGH ARCHITECTURAL DESIGN: A KEY POINT CONTROLLED METHOD ${ }^{1}$
}

\author{
Romy Guruz ${ }^{1}$, Raimar Scherer ${ }^{2}$ \\ Technische Universität, Dresden, Germany

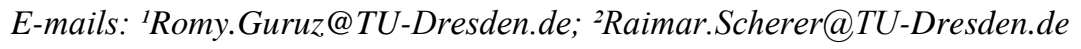 \\ Received 20 September 2014; accepted 26 October 2014
}

\begin{abstract}
The biggest opportunity to influence the relationship between energy goals and architectural design is during the early planning phases of a building project. It is commonly known that unilateral elaborate design decisions can have substantial negative influence on the economic and the environmental performance of a building. Great opportunities are seen in the early design phase, where only general conditions and basic constraints are predetermined by the client and the participating planners. Building requirements contain numerous explicit and implicit requests, which can in a next step be defined as verifiable design checkpoints. These Key Points will allow designers to easily structure the design process in individual evaluable parts and will thus help them to concentrate on high-level strategic decision making tasks. Against this background, the central question that motivates this paper is: how can we aggregate building requirements to be able to formalize the data as basis for the definition of Key Points? To answer this question, a closer look at building requirements of different participating planners and their individual decision making is taken. The Key Point driven design process is expected to lead to greater efficiency in the planning procedure to final design results of higher quality. At the same time, it will provide an opportunity of weighing up many more alternatives than currently possible.
\end{abstract}

Keywords: sustainable energy entrepreneurship, Key performance indicators (KPIs); building requirements; decision making; process pattern; key design points

Reference to this paper should be made as follows: Guruz, R.; Scherer, R. 2014. Sustainable energy entrepreneurship through architectural design: a key point controlled method, Entrepreneurship and Sustainability Issues 2(2): 60-73.

DOI: http://dx.doi.org/10.9770/jesi.2014.2.2(2)

JEL Classifications: $\mathrm{O} 180$

\section{Introduction}

Sustainable energy entrepreneurship from both, supply and demand sides, i.e. from side of architects designing energy-efficient buildings, and from side of entrepreneurs, who develop other activities in those buildings, significantly depends on approach, which has been used for buildings design (Laužikas, Mokšeckienė 2013; Vosylius et al. 2013; Bileišis 2014, Dzemyda, Raudeliūnienė 2014; Korsakienè, Tvaronavičienė 2014; Litvaj,

\footnotetext{
1 This paper reveals the ongoing PhD thesis of the first author under the supervision of the second one. The research presented in this paper was enabled by the financial support of the European Commission to the eeEmbedded project under Grant Agreement \#609349. This support, as well as the support of the project partners, is gratefully acknowledged.
} 
Poniščiaková 2014; Raudeliūnienė et al. 2014; Tvaronavičienė 2014; Tvaronavičienė et al. 2014; Vasiliūnaitė 2014; Scherer, Schapke 2011).

The presented in the paper tackles this issue by introducing eeEmbedded system, which will comprehend a Key Point-controlled holistic design methodology, and evolve an integrated information management framework for designing energy-efficient buildings and their optimal energetic embedding in the neighbourhood of surrounding buildings and energy systems. Building Information Model (BIM) will thereby be complemented by a newly developed Energy System Information Model (ESIM) based on the principles of the BIM-IFC (ISO 16739) standard and subsuming existing proprietary energy system models, and an extended Building Automation and Control System (BACS) model integrated with BIM, following the suggestions collaboratively elaborated in the FP7 projects HESMOS (09/2010-12/2013), SEEDS (09/2011-08/2014) and ISES (12/2011-11/2014).

Existing information representation gaps will be filled and the BIM methodology will be extended to an energyenhanced embedded BIM methodology (eeeBIM). The domain models BIM, ESIM, BACS (see Figure 1) will provide: (a) the eeeBIM information framework for a holistic architecture and energy design of buildings embedded in the energetic neighbourhood, and (b) the baseline of the information collaboration between the involved different specialists, namely building designers, construction engineers, facility managers, energy designers, fluid dynamic engineers, control engineers, etc. The design of the energy system and of the energyefficient behaviour of buildings that are optimally embedded in their energetic surroundings has a broad interdisciplinary scope. It requires intensive collaborative work of many different discipline experts and special management capabilities to manage and control the complex, evolving design process.

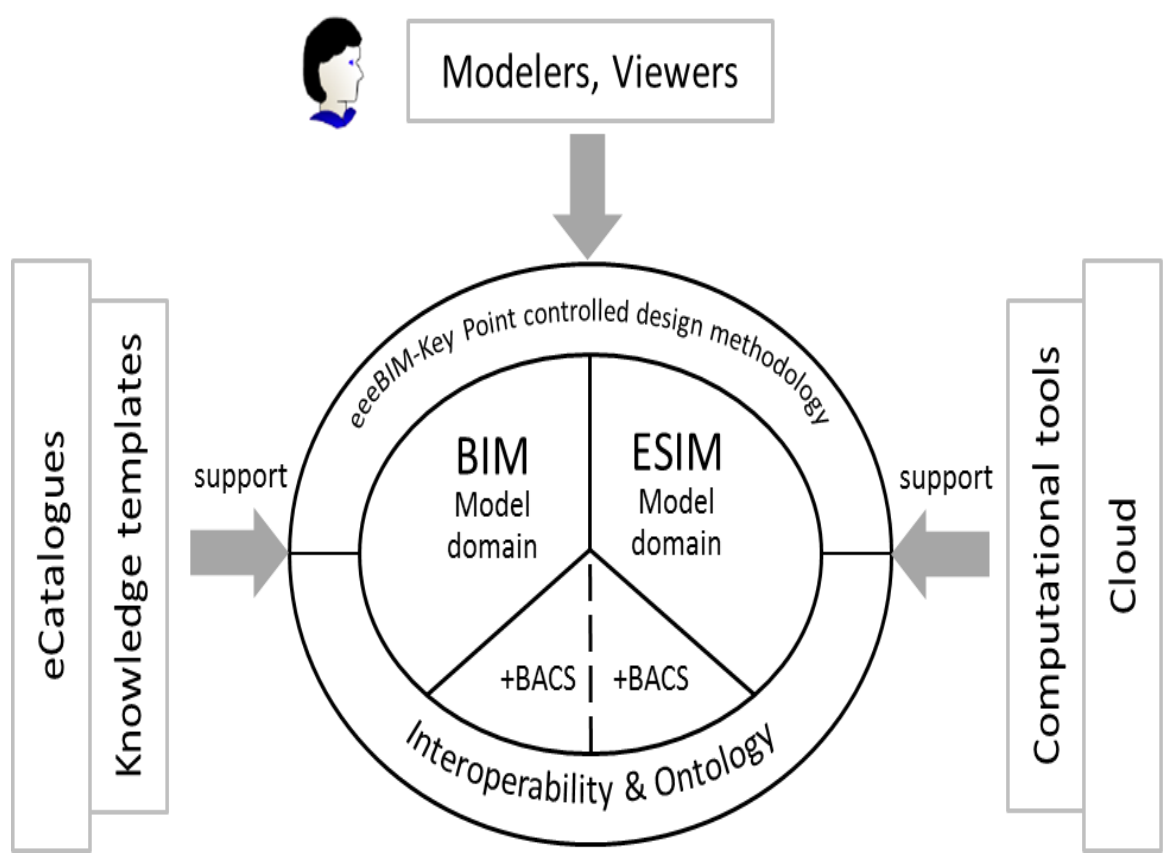

Fig.1. eeEmbedded System - Concept of the Collaborative Holistic Design Lab, embracing the 3 domains BIM, ESIM and BACS

To guide the multi-disciplinary design process and to focus on reaching the optimum value for the client as fast as possible, first a vision of a Key Point controlled design methodology has to be developed, which allows constant control and monitoring of the complex design process.

The main objective of this research is the examination of building requirements for the achievement of a consistent Key Point definition. For the purposes of this development, the term Key Points will be taken to mean verifiable design checkpoints. This term refers to Key Performance Indicators (KPIs), which are simple numeric metrics of 
energy usage or observed building characteristics that can be associated with better or worse energy performance. Similar to KPIs in other business organizations these KPIs are intended to yield the best information for the minimizing costs and analysis time. This enables the planners to better understand the impact of their design choices and moreover provides them a simple framework to reference when defining requirements for energy monitoring equipment and analysis for their new (or existing) building project (Harris and Higgins 2012).

The central question then becomes: if KPIs are integrated in the design process to check energy performance by means of simulation tools, are there any further "Key" requirements which can be used in defining design checkpoints and design process milestones? And which requirements do they have to fulfil that makes them capable of being checked? The vision of our new design methodology necessitates a net of verifiable design checkpoints, which are based on building requirements and during the different design phases used as milestones which are defined as Key Points.

In the first part of the paper, we discuss the basis interdependencies of the Key Points between building requirements, domain models and the scopes of action to get an overview of the components of the preferred new design process. These are reported in more detail in the third section about process pattern.

In the second part, we suggest a stepwise aggregation of building requirements to derive the Key Points. The more requirements and principles are defined in the front-end, the simpler it will be to fix target values in the stage of the definition of Key Points. Therefore, the Key Points are hierarchically categorized:

Key Design Requirements (KDRs)

Represent the mandatory building requirements and usually have a limited value.

Key Design Parameters (KDPs):

Represent the plan values, which are to be introduced by the domains after their domain related tasks.

Key Performance Indicators (KPIs):

Represent the simulation results after comparing and ranking.

Decision Values $(D V s)$ :

Represent the preferences of the decision-makers related to the project goals. This allows prioritising KPIs by means of a weighting factor.

In the third part, the results will be examined for recurrent pattern to facilitate general automation of the different process steps in each design phase. We reduce the diversity process to three generic process patterns unfailingly applicable to our method. We introduce a 3-step control and monitoring system, which is combined with the newly developed requirements aggregation structure. We show how the governing KDIs, KPIs and DVs can be applied to a variety of tasks within their patterns.

Finally, we present an example of how to express the Key Points in terms of KDRs, KPIs and DVs regarding the different domains with a use case. These initially identified KDRs, KPIs and DVs form a basis for the integration and synthesis to a coherent overall design method.

\section{Basis interdependencies of the Key Points}

The key point controlled design methodology will prepare the existing simulations and analyses tools for an integrated holistic design system and will combine them to an interoperability design framework serving the complex multi-information model and multi-physics demands. The purpose of the methodology is to guide through the numerous design options and help choosing the best ones in the shortest time possible (Guruz et al. 2012; Eastman et al. 2011). 
Basis of each design decision are the predetermined building requirements. After formalization of the Key Points, as target elements for the following analyses, conclusions can be drawn with regard to domain models and the related elements and the inputs for the analyses can be prepared. As shown in Figure 1, upon completion of the design cycle, the analysis step of the decision cycle, the results are validated against the building requirements. In addition to the consequences for the domain models, the quality of the results should be evaluated here as well. The challenge is to develop an IT and BIM based combination of evaluation for the next design steps. To achieve the envisaged functionality, methods are being developed to formalize and resolve each single step in a pattern.

The design processes have been analysed to identify the different decision making as basis for the development of the 3 step design method. In a first step the tasks have been divided in the different cycles, with regard to various process conditions:

1. Design cycle: this includes the architecture domain, the energy system domain, the Heating, Ventilation and Air Conditioning (HVAC) domain, the Building Automation and Control System (BACS) domain and the (Facility Management) FM domain.

2. Simulation (Analysis) cycle: this includes the simulation domain, the Life Cycle Assessment (LCA) domain and the Life Cycle Costing (LCC) domain.

3. Decision cycle: The developer/owner/or one of the experts above (in most cases the architect) decides if the concept developed by the project team is worth implementing.

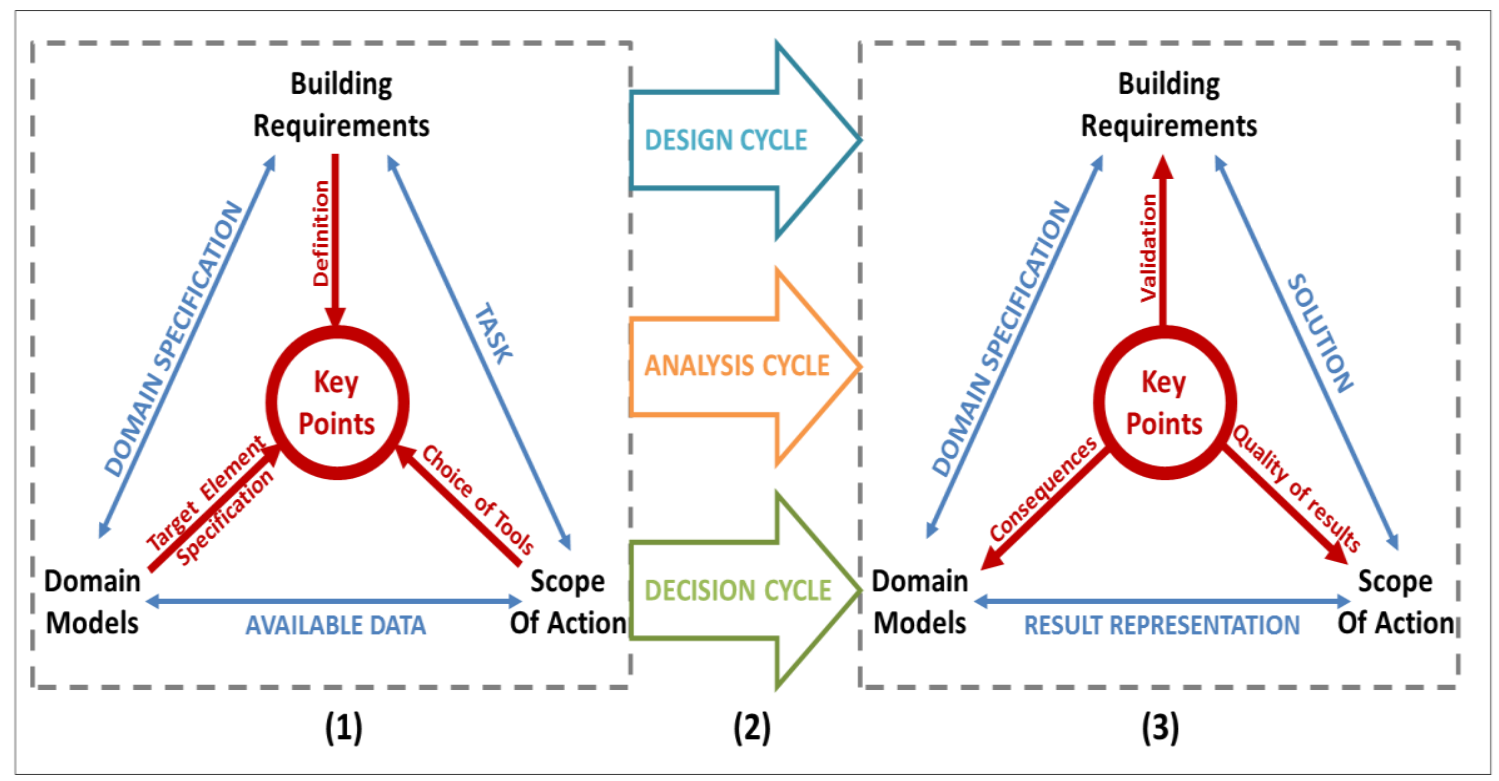

Fig.2. General interdependencies between Key Points, building requirements, domain models and variable scope of actions in (1) Definition (2) trough tasks and in (3) Validation

As shown in Figure 2 in the left part (1), the Key points were defined from building requirements depending to the related task. The middle part (2) and the right part (3) are strongly related to each other: three different task cycles are supported: Design Cycle: the design variants and alternatives are verified.

Simulation/Analysis Cycle: the building performance alternatives are compared and/ or ranked.

Decision Cycle: the final alternatives are weighted evaluated.

\section{Building Requirements as Basis for Key Point Evolution}

Regardless of the complexity of the methods we use to make our decisions, the basis of each of them are the predetermined requirements. They are the basis of each project and define its characteristics. Consequently, the 
stepwise refinement of requirements with the possibility to verify results at predefined Key Points would result in a continuous monitored planning process.

\subsection{General Steps towards Identification of Requirements}

Primary, the description of building requirements in the first step varies depending on the client, the type and the size of the project. In addition, country specific factors, laws and regulations determine the valences of the individual requirements. During the requirements specification process the regulatory requirements, the environmental requirements and the client desires as well as the site requirements are translated into building and design requirements. After defining the main concepts of a building in cooperation with the client, in the second step the initial conceptual design is worked out by the different domain experts. They are determining subjectrelated bases in the required project scope, depth and quality.

At third step of these considerations is to clarify, which kind of requirements, information and knowledge is needed within our patterns to support a task related decision making. We generally expect that the domain experts are going to translate the various requirements into (their) design requirements, which are the basis for common domain related tasks. Lastly, in the fourth step, the alignment of the worked out building requirements, a consistent check is needed. Eventually, after completing a planning phase, this step is repeated and stepwise refined.

\subsection{Building Requirements Aggregation to Key Points}

To enable structured definition and formalization of Key Points via rules and/or algorithmic constituents, first the building requirements have to be appropriately categorized. Figure 3 shows the overall concept for a key point controlled design methodology based on hierarchically structured dynamic evolving decision points, expressed in aggregated requirements. The pyramid shows the generic structure of requirements aggregation related to 4 main tasks in design. The requirements level on the bottom of the figure 3 starts the progress.

\section{Aggregation:}

Based on the client, regulatory, site requirements (etc.) and all involved design partners, the key requirements need to be translated, developed and reported in a structured way. The results of this process, in which each participating design partner is involved, are described as Key Design Requirements (KDRs), shown in the right side of the figure. To verify compliance with the design objectives and specifications the requirements should be translated to Key Design Requirements (KDRs). As part of this process step, the KDRs are also finally checked and matched within the participating domains.

\section{Aggregation:}

The KDRs guide the design, by inclusion (build it this way) or exclusion (don't build it this way), and are used for ruling out different design options. In the domain task level, where all domains start their iterating working cycles, the KDR are used as target values for verification of the alternatives, for tracking the design process.

KDRs represent the mandatory requirements and usually have a limited value.

The plan values, which are to be introduced by the domains after this working step, are expressed in Key Design Parameters (KDPs).

\section{Aggregation:}

The third aggregation takes place during the simulation and analysis tasks. The KDPs are uses for comparing and ranking the simulation results, which are defined as Key Performance Indicators (KPIs). To compare the design variants and alternatives regarding their sustainable performance, relevant KPIs have to be introduced. For elaborated comparisons, the simulation, Life Cycle Assessment (LCA) and Life Cycle Costing (LCC) experts develop based on the requirements their KDPs to evaluate the performance in their field of expertise. With KPIs alone it is possible to make a statement on how well a design alternative or option performs regarding a specific goal. With the KPIs structured according to the ecological (final energy and emissions), socio-cultural (thermal comfort and air quality) and economic (investment and operational costs) target-quality, different alternatives can be compared to identify the one with the best cost-quality ratio. KPIs offer the possibility to quantify the 
performance of measurable indicators as well as of qualitative indicators. They are defined relative deviations from before-hand agreed KDRs.

\section{Aggregation:}

The last aggregation is in higher decision making. For weighted evaluation the KPIs have to be aggregated to Decision Values (DVs). The preferences of the decision-makers vary, so they need the possibility to prioritise KPI with a weighting factor. The DVs comprise the weighted ecological (final energy, primary energy, etc.), sociocultural (temperature over-/underruns, etc.) and economic (investment, maintenance and energy costs) KPI regarding their priority for the project.

With KPIs alone it is possible to make a statement on how well a design alternative or option performs regarding a specific goal. To evaluate the results from different domains and priories, the results have to be weighted in the direction of the project goal. This methodology with an appropriate precision is needed for the controlled multidisciplinary design. Variants or alternatives with the best score are selected as the basis for the next development stage.

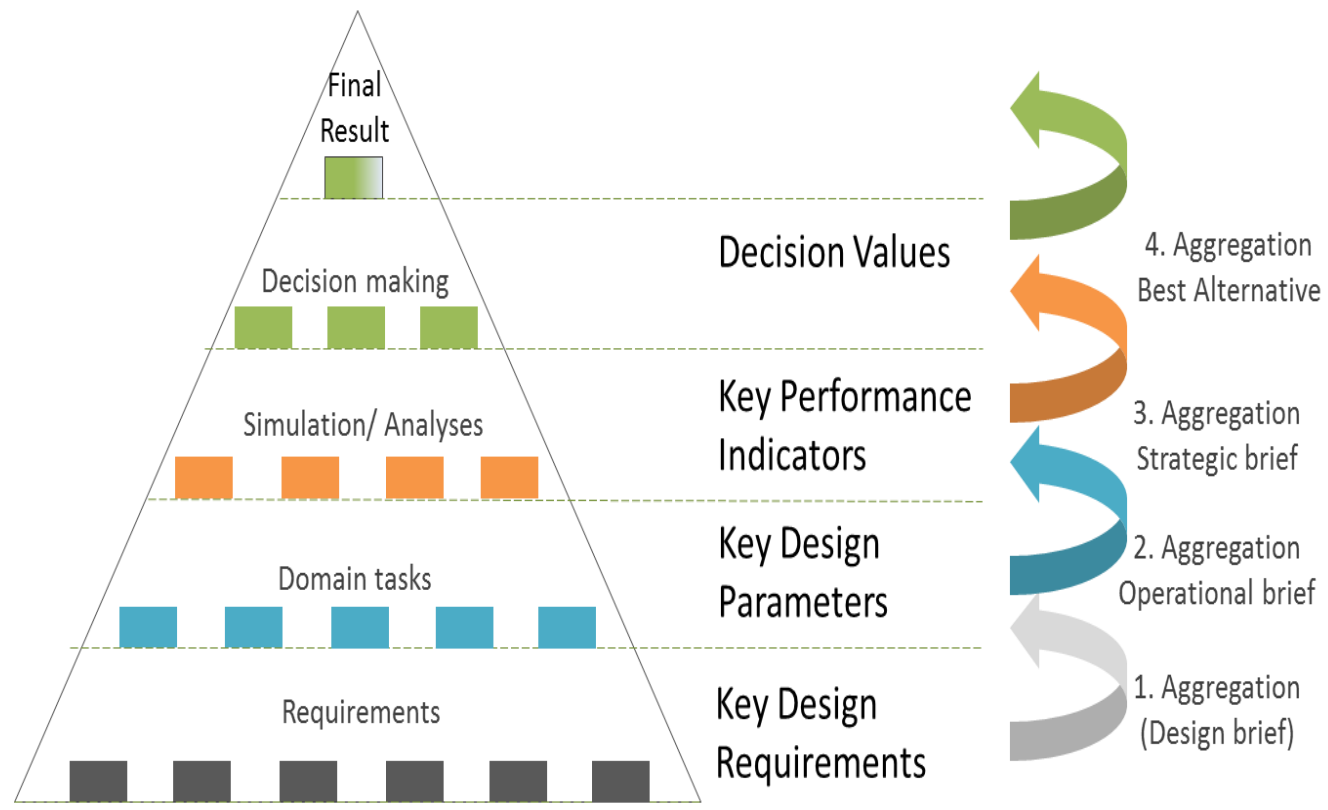

Fig.3. Step wise requirements aggregation 


\subsection{Building Requirements to Key Points}

The design goals for the suggested Key Points should be developed in a structured briefing process top down starting from requirements to the technical brief, and then operational brief, and summarised in the strategic brief as shown in Figure 4.

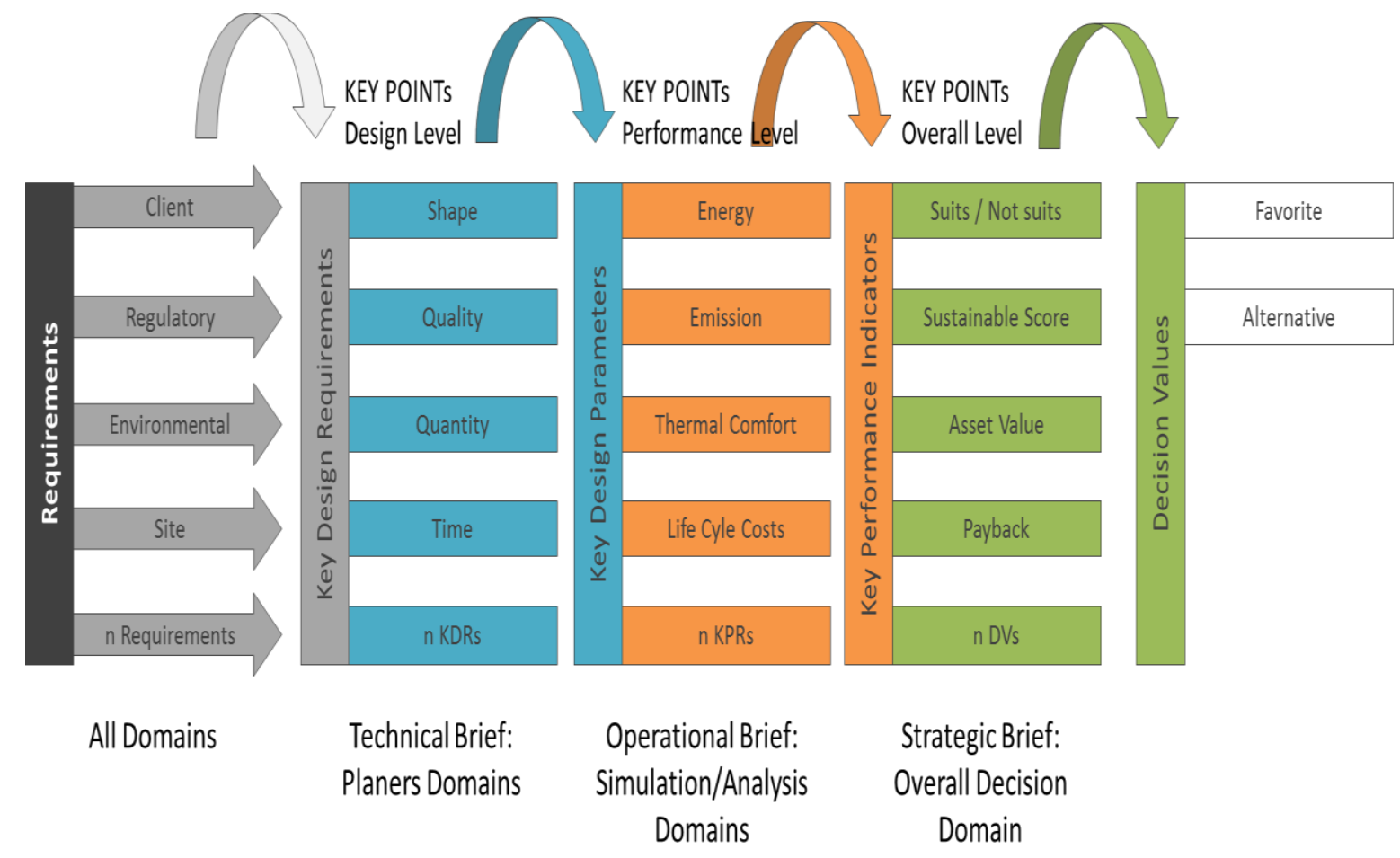

Fig.4. Schema briefing process based on KDRs, KDPs, KPIs and DVs

In the technical brief, Key Design Requirements (KDR) need to be developed based on the client, regulatory, site and design partner requirements in a structured way.

Their Key Points are in the design level, and are described as Verification Points and it will be checked:

- Have we made what we were trying to make?

- Does the building/ energy system conform to the specifications?

Key Design Parameters - qualitative and quantitative aspects of the design - are used to verify (model-based) that the design is created to fulfil the requirements.

In the operational brief, Key Design Parameters are derived from the regulatory, site and environmental requirements and also from former results. The KDPs describe the level of performance in solution independent terms that must be reached to achieve the clients' project goal.

Their Key Points are in the performance level, and are described as Validation Point and it will be checked:

- Are we trying to make the right thing?

- Is the product specified to the user's actual needs?

Key Performance Indicators - performance measurements - are processed from the stochastic simulations and analysis and validate against target-performance.

In the strategic brief, Key Performance Indicators are established and weighted very carefully based on the project goal to judge the impact of design solutions considered and to protect what is most important during the decision making process. 
Their Key Points are in the performance level, and are described as Decision Points; the choice is made based on the values and preferences of the decision maker.

The Decision Value - ratio of function (comfort, flexibility, energy savings, fewer emissions, aesthetics etc.) per life cycle costs - is processed by weighting results of different domains regarding the preferences and is then used for the final decision.

\subsection{Criteria for using building requirements}

In general, three types of requirements can be distinguished:

a) Requirements that are difficult to formalize (because they describe, e.g. an impression like "relations of different views"),

b) Requirements that allow drawing direct conclusions, such as space use, furniture concept etc., and

c) Requirements that can be formalized as facts (values, value ranges, rules, fixed algorithms). This has influence on the scope of the potential key points in respect of the verifiability (Figure 5).

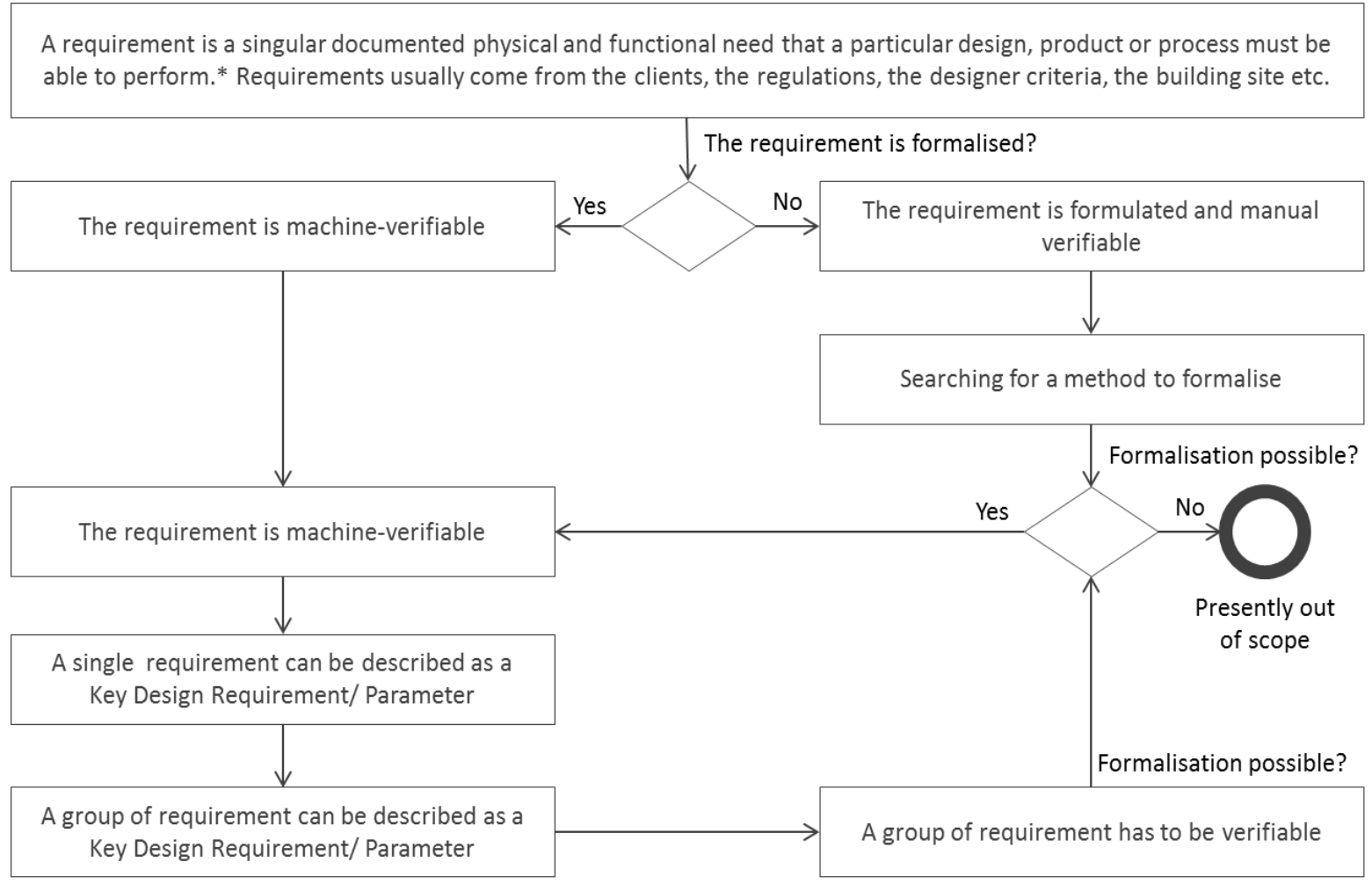

Fig.5. Basis requirements test within the design level

\section{Key Points in generic Design Pattern}

Based on the worked out use cases for the eeEmbedded system and with regard to various process conditions, the different domains are divided in 3 levels with different ways of decision making:

1. Experts' Level: includes the architecture, the energy system, the HVAC domain, the BACS domain and the FM domain:

Verification: Discarding design options by reducing those to the ones which meet the domain related KDRs. 
2. Simulation and Analysis Level: includes the simulation domain, where experts perform the required simulations to optimise the design concepts; the LCA domain, where LCA consultants estimate the lifetime environmental impact and the LCC domain, for estimating the whole life cycle costs of the building and its systems.

Domain-related decision making: Comparing and/or ranking of simulation/ analysis results with assistance of KPIs.

3. Decision-making Level: The developer/owner/ or one of the experts above (in most cases the architect) decides if the concept developed by the project team is worth implementing.

Overall decision making: Prioritisation of decision criteria with goal oriented DVs (e.g. using hierarchies of domain experts' perspectives).

As a result of this classification, we precisely examined these levels to reduce complexity by inference and derivation of complex tasks and decision-making in a generic process. For each of the above levels, a pattern could be created with special attentions to our overall objective: i.e. to support the different decision-making.

The three elaborated patterns can be described as follows:

I. Input conditions: aggregated requirements and additional requirements, as well as models by other domains and results of former iterations. These conditions are split in mandatory and optional sets;

II. Process starting point;

III. The individual process task (usually initiated by requirements) produces results;

IV. Results (different Alternatives);

V. KEY POINT: decision-making within the pattern related to evaluation of the results;

VI. Process end point;

VII. Output conditions: also separated in mandatory and optional sets- typically results, transferred as domain model, as well as further requirements (depended on aggregation level).

Therefore, each design phase can be described with the 3 patterns: Domain task pattern, simulation/computation pattern and the decision making pattern. In front of the different methods and strategies existing in the decision theory, it is necessary to further define the characteristics and restrictions of the decision challenge.

\subsection{Pattern 1: Design verification with Key Design Requirements}

Every domain expert should be able to set up the specific requirements in a structured way and refine them throughout the design process. To verify compliance with the design objectives and specifications the requirements should be translated to KDRs. KDRs are requirements' measures which are used for tracking the design process. KDRs represent the mandatory requirements and usually have a limited value (Figure 6).

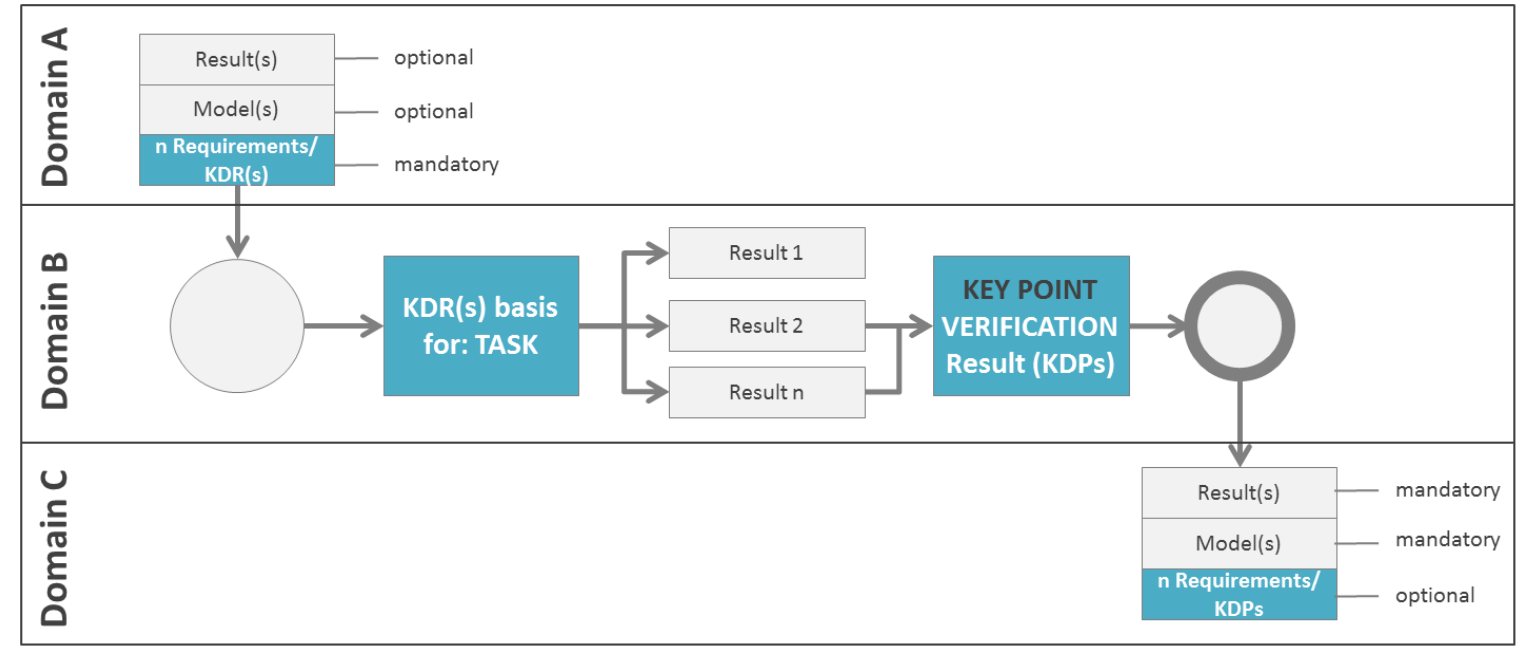

Fig.6. Fully described "Pattern 1" including KDR decision making as BPM 
Verification: Discarding design options by reducing those to the ones which meet the domain related KDRs.

I. Input conditions: Mandatory: $\boldsymbol{n}$ requirement(s) expressed in KDRs

Optional: Former domain results / models

III. Process task: Task related to $\operatorname{KDR}(s)$

V. Key Point: Verification results (alternatives);

If the result constitutes a required target (value) for simulation/ analyses, then it's a mandatory output for the following key point.

VII. Output conditions: Mandatory: Domain results/model(s)

Optional: Alternatives; Further requirements (KDPs)

\subsection{Pattern 2: Performance optimization - Key Performance Indicators}

This pattern supports the optimisation of the performance of building developments based on Key Design Parameters (KDPs) (Figure 7). With the result KPIs structured according to the ecological (final energy and emissions), socio-cultural (thermal comfort and air quality) and economic (investment and operational costs) quality different alternatives can be compared to identify the one with the best cost-quality ratio. KPIs offer the possibility to quantify the performance of measurable indicators as well as of qualitative indicators. They are defined relative deviations from beforehand agreed target value (Schreyer et al. 2010).

Domain-related decision making: Comparing and/or ranking of simulation/ analysis results with assistance of KPIs.

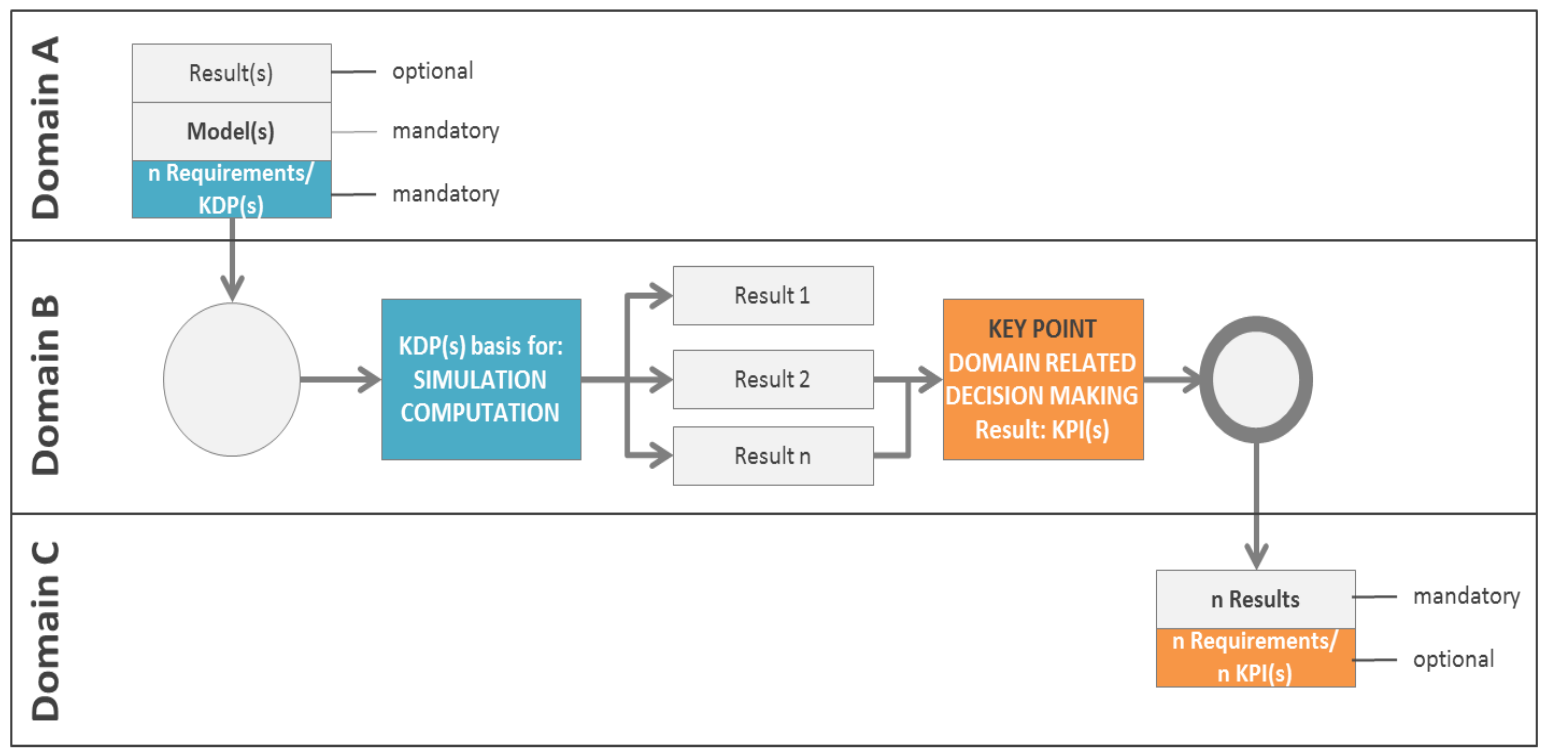

Fig.7. Fully described "Pattern 2" including KPI decision making as BPM

I. Input conditions: Mandatory: $n$ requirement(s) expressed in KDPs

Optional: Former domain results / models

III. $\quad$ Process task: $\quad$ Simulation/ Analysis related to $K D P(s)$

V. Key Point: $\quad$ Comparing results via KPIs (alternatives);

If the result constitutes a required target (value) for overall decision making, then it's a mandatory output for the following key point.

VII. Output conditions: Mandatory: Domain results/model(s)

Optional: Alternatives; Further requirements (KPIs) 


\subsection{Pattern 3: Prioritisation and decision making with Decision Values (DV)}

DV comprise the weighted ecological (final energy, primary energy, GWP etc.), socio-cultural (temperature over/under-runs, PMV/PPD etc.) and economic (investment, maintenance and energy costs) KPI regarding their priority for the project. With KPIs alone it is possible to make a statement how well a design alternative or option performs regarding a specific goal (Schreyer et al. 2010). To evaluate the results from different domains and priories, the results have to be weighed in the direction of the project goal. This methodology with an appropriate precision is needed for the controlled multi-disciplinary design (Figure 8).

Overall decision making: Prioritisation of decision criteria with goal oriented DVs (e.g. using hierarchies of domain experts' perspectives).

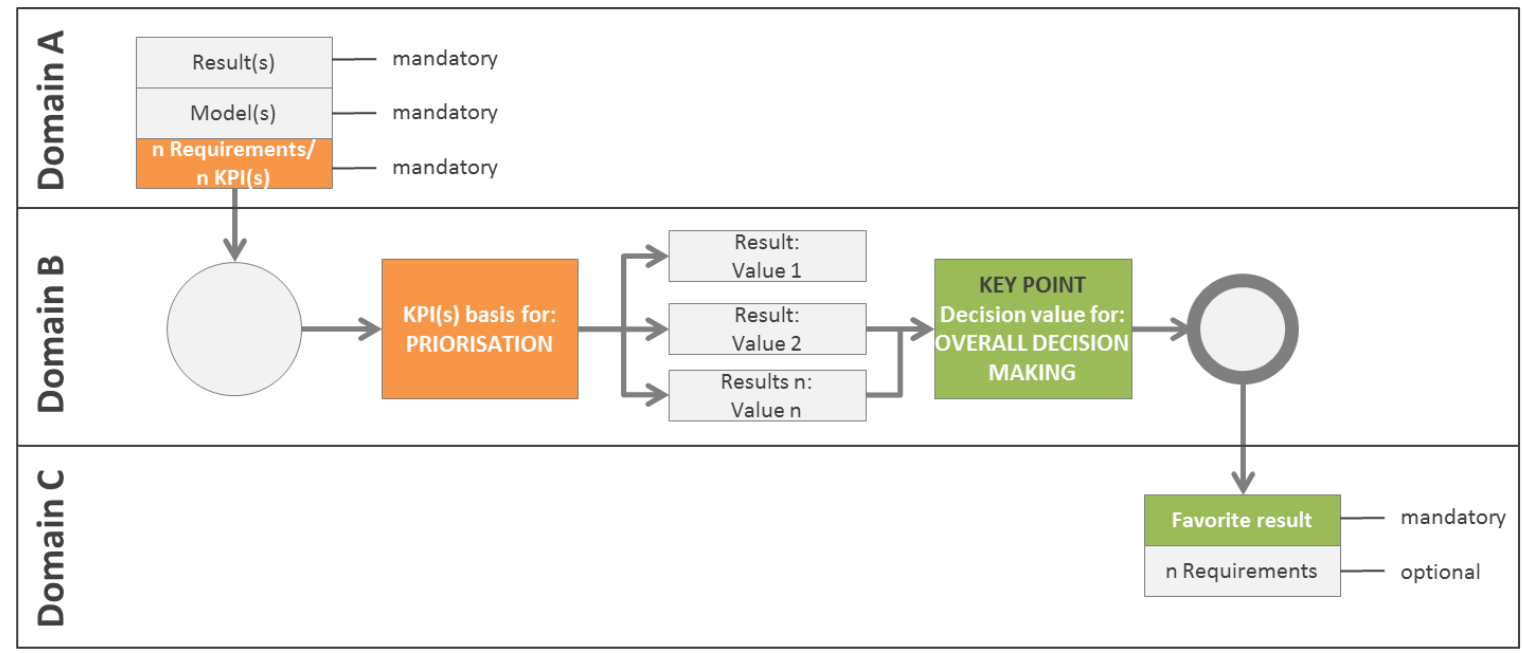

Fig.8. Fully described "Pattern 3" including DV decision making as BPM

I. Input conditions: Mandatory: $n$ requirement(s) expressed in KPIs,

Domain results and Model(s)

III. Process task: $\quad$ Prioritisation related to KPI $(s)$

V. $\quad$ Key Point: $\quad$ Overall decision making via DVs (alternatives);

VII. Output conditions: Mandatory: favourite result Optional: $\boldsymbol{n}$ requirements.

\section{Example for preliminary urban design}

The following example was worked out in context of the EU project eeEmbedded in collaboration end users (Geißler et al. 2014). The represented use case "Urban design" has the aim of designing the most optimal energetic embedding in the neighbourhood which comprises the definition of the building envelope geometry and the district energy system, as well as its colour-coded Key Points (Figure 9).

To express the Key Points of the design process in terms of KDRs, KPIs and DVs regarding the different domains for the Urban Design Phase, $e e \mathrm{E}$ examples are given in the Table 1. These initially identified KDRs, KPIs and DVs form a basis for the integration and synthesis to a coherent overall design method. 


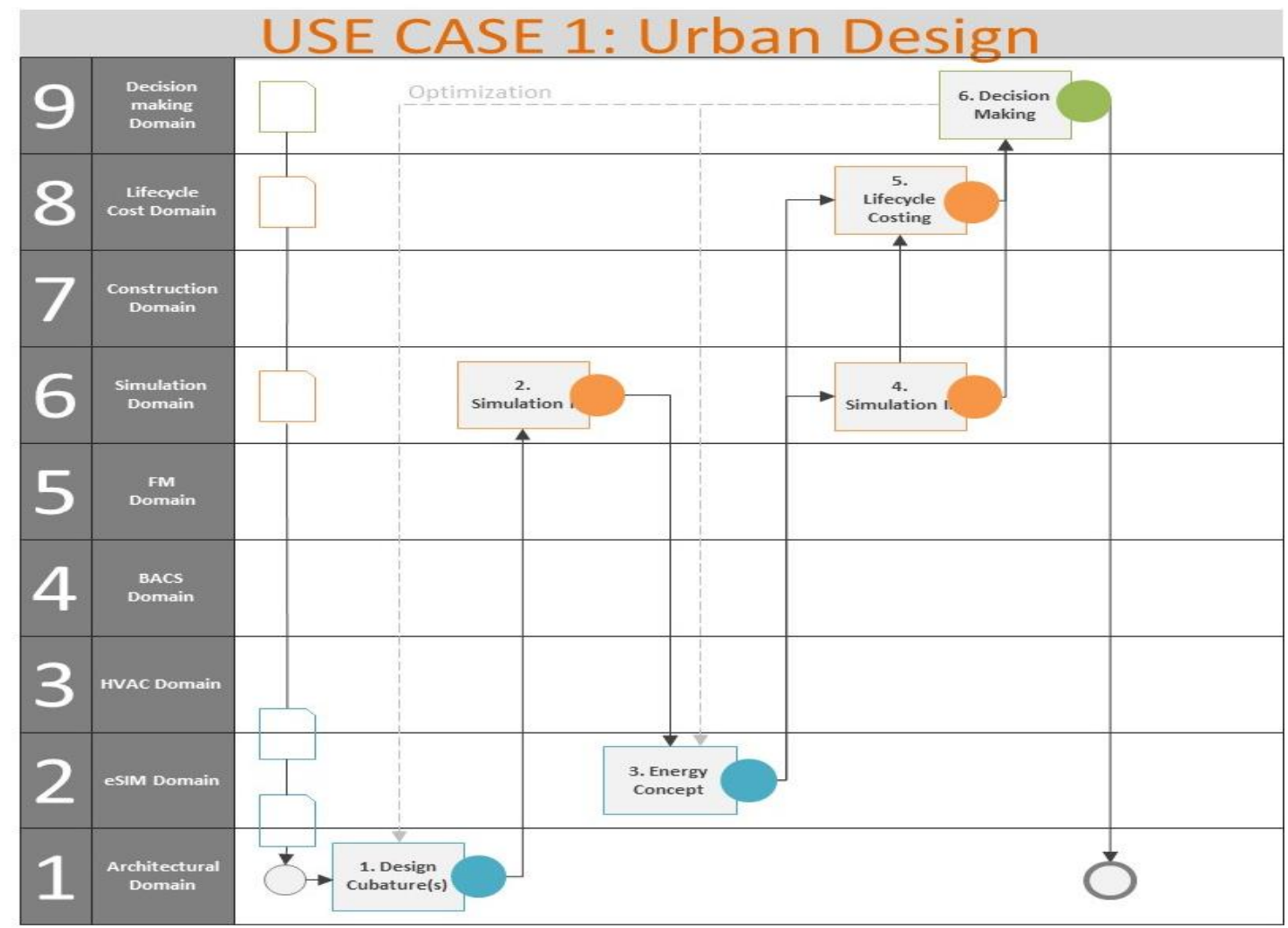

Fig.9. Simplified representation of the use case with color-coded Key Points

Table 1. eeEmbedded: KDR/KPI/DV examples for Urban Design

\begin{tabular}{|c|c|c|}
\hline Domain & Type & eeEmbedded examples \\
\hline 1 Architectural & KDR & 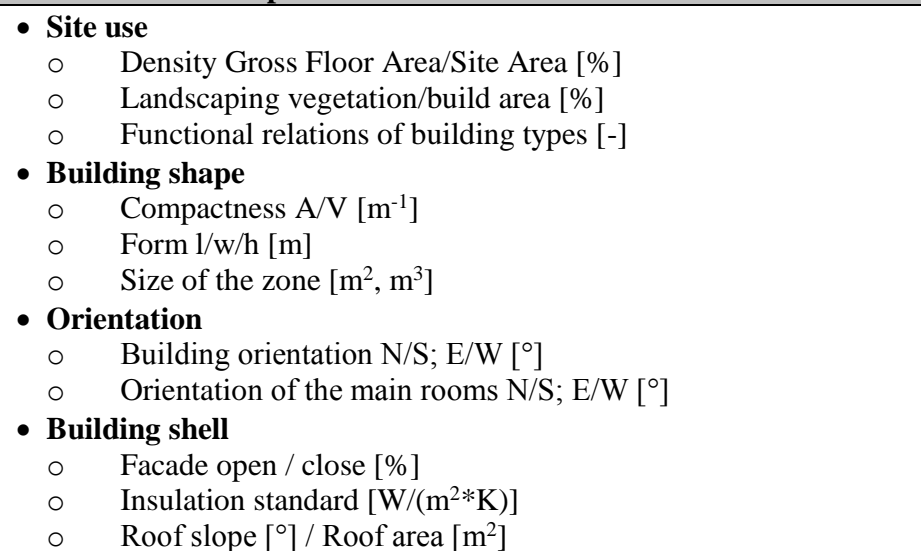 \\
\hline 6 Simulation & KPI & $\begin{array}{l}\text { - Cooling and heating demand - net energy }\left[\mathbf{k W h} / \mathbf{a}, \mathbf{k W h} /\left(\mathbf{m}^{2} \mathbf{x} \text { a)] }\right.\right. \\
\circ \text { Solar gains }\left[\mathrm{W} / \mathrm{m}^{2}\right] \\
\circ \text { Heat losses / cooling losses }\left[\mathrm{kWh} /\left(\mathrm{m}^{2} \mathrm{xa}\right]\right. \\
\circ \text { Peak loads }[\mathrm{kW} ; \mathrm{kW} / \mathrm{m} 2] \\
\text { - Comfort Conditions } \\
\circ \text { Physiological Equivalent Temperature }\left[{ }^{\circ} \mathrm{C}\right] \\
\circ \text { Air flow rate }\left[\mathrm{m}^{3} / \mathrm{h}\right] \\
\circ \text { Shading / Daylight }[\%, \text { unit } / \mathrm{h}]\end{array}$ \\
\hline 2 Energy System & KDR & $\begin{array}{ll}\text { - } & \text { Renewable energy } \\
\circ & \text { On-site renewables (ground, solar, wind, biomass) [\%] } \\
\circ & \text { District heating and cooling [\%] } \\
\circ & \text { Waste heat [\%] }\end{array}$ \\
\hline
\end{tabular}




\begin{tabular}{|c|c|c|}
\hline \multicolumn{3}{|c|}{ Use Case 1: Urban Design } \\
\hline Domain & Type & $e e$ Embedded examples \\
\hline & & 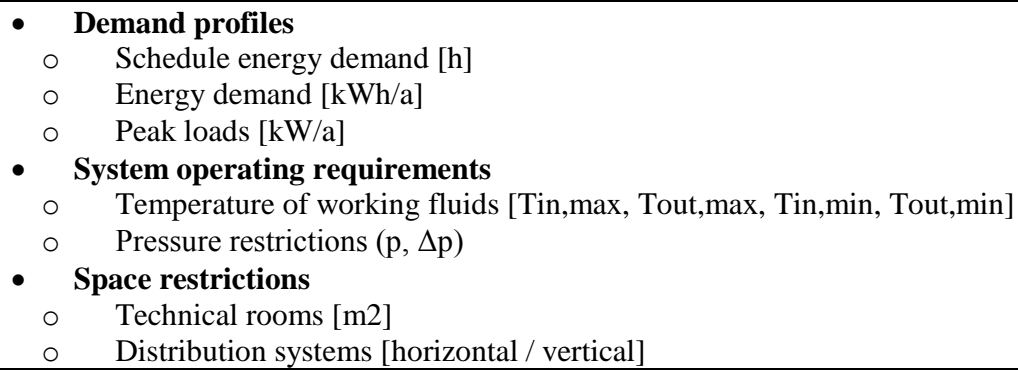 \\
\hline 6 Simulation & KPI & $\begin{array}{ll}\text { - } & \text { Energy consumption }\left[\mathbf{k W h} / \mathbf{a}, \mathbf{k W h} /\left(\mathbf{m}^{2} \mathbf{x} \mathbf{a}\right), \mathbf{T o p} / \mathbf{a}, \mathbf{T o p} /\left(\mathbf{m}^{2} \mathbf{x} \mathbf{a}\right)\right] \\
\circ & \text { Overall efficiency [\%] } \\
\circ & \text { Percentage of thermal energy demand covered [\%] }\end{array}$ \\
\hline 8 Life Cycle Costing & KPI & $\begin{array}{l}\text { - Life Cycle Costs }[€] \\
\circ \quad \text { Investment costs }[€] \\
\circ \quad \text { Operation costs }[€] \\
\circ \quad \text { Maintenance costs }[€] \\
\text { - Payback [a] } \\
\end{array}$ \\
\hline 9 Decision-making & DV & $\begin{array}{l}\text { - Principle decision [suits / do not suit] } \\
\text { - Sustainable score [medal] } \\
\circ \quad \text { Ecological quality [points/total points of category] } \\
\circ \quad \text { Socio-cultural quality [points/total points of category] } \\
\circ \quad \text { Economical quality [points/total points of category] } \\
\text { - } \\
\text { Asset value }[€]\end{array}$ \\
\hline
\end{tabular}

\section{Conclusions and further work}

In this paper a new concept for a holistic design methodology was presented based on hierarchically structured dynamic evolving Key Points, expressed in aggregated requirements: KDRs, Key Design requirements for ruling out options for domain related tasks, KPIs, Key performance indicators for performance evaluation and optimization, and finally DVs, Decision Values for prioritisation and decision making. This design method is proposed to guide and monitor the progress of the multi-disciplinary, multi-model and multi-physics design process. The holistic design methodology approach has been chosen to optimize the design path and design process as well as increase coordinated decision-making.

In a next step, building requirements will be classified, and represented, in a taxonomy structure. In parallel, Key Design Requirements, Key Requirement Parameters as well as Key Performance Indicators will be examined in taxonomies to find multi combinations regarding to the building requirements.

The proposed approach is currently under development and is also being extended from the results of the European FP7 projects HESMOS (2010-2013) and ISES (2011-2014) in the direction of a multi-model energy enhanced BIM framework (eeBIM). The outlined concept for a holistic design methodology will be intensively further investigated, elaborated and validated in the frames of the eeEmbedded project. The requirements and specifications of the new design methodology and the new (ICT) combined virtual design office for teamwork collaboration and the virtual design lab for energy analysis and simulation will be developed are current under development. The development of the supporting information and communication technology (ICT) methods, namely the collaborative holistic design lab and office will start in autumn 2014. Development and implementation of this new building design methodology would have significant implication for sustainable energy entrepreneurship, which is significant driving force of sustainable development process.

\section{References}

Bileišis, M. 2014. Public Sector Control as a Factor in Entrepreneurial Policy: the Case of Lithuania, Entrepreneurship and Sustainability Issues 1(3): 151-161. DOI: http://dx.doi.org/10.9770/jesi.2014.1.3(4) 
Korsakienè, R.; Tvaronavičienė, M. 2014. Processes of economic development: case of Lithuanian real estate sector, Entrepreneurship and Sustainability Issues 1(3): 162-172. DOI: http://dx.doi.org/10.9770/jesi.2014.1.3(5)

Dzemyda, I.; Raudeliūnienè, J. 2014. Sustainable youth entrepreneurship in conditions of global economy toward energy security, Entrepreneurship and Sustainability Issues 1(4): 247-256. DOI: http://dx.doi.org/10.9770/jesi.2014.1.4(7)

Eastman, C.; Teicholz, P.; Sacks, R.; Liston, K. 2011. BIM Handbook: A Guide to Building Information Modeling for Owners, Managers, Designers, Engineers and Contractors. John Wiley \& Sons. 2nd edition.

eeEmbedded [online], http://www.eeEmbedded.eu.

eeEmbedded 2013-17, EU FP7 Project No. 609349.

Geißler, M.C.; Guruz, R.; van Woudenberg, W. 2014; eeEmbedded Deliverable D1.1: Vision and requirements for a KPI-based holistic multi-disciplinary design, (C) eeEmbedded Consortium, Brussels.

Guruz, R.; Katranuschkov, P.; Scherer, R.J.; Kaiser, J.; Grunewald, J.; Hensel, B.; Kabitzsch, K.; Liebich, T. 2012. Ontological Specification for the Model Integration in ICT Building Energy Systems, to be published in: Proceedings of the 9th European Conference on Process and Product Modelling, 25-27.07.2012, Reykjavik, Iceland.

Harris, D.; Higgins, C. 2012. Key Performance Indicators and Analysis for Commercial Buildings with System Level Data, New Buildings Institute. Available on the Internet: <http://newbuildings.org/kpi>.

Laužikas, M.;Mokšeckienè. 2013. The role of creativity in sustainable business, Entrepreneurship and Sustainability Issues 1(1): 1022. DOI: http://dx.doi.org/10.9770/jesi.2013.1(2)

Litvaj, I.; Poniščiaková, O. 2014.Entrepreneurship and quality management, Entrepreneurship and Sustainability Issues 1(4): $204-209$. DOI: http://dx.doi.org/10.9770/jesi.2014.1.4(2)

Raudeliūnienè, J.; Tvaronavičienè, M.; Dzemyda, I. 2014. Towards economic security and sustainability: key success factors of sustainable entrepreneurship in conditions of global economy, Journal of Security and Sustainability Issues 3(4): 71-79. DOI: http://dx.doi.org/10.9770/jssi.2014.3.4(7)

Scherer, R.J.; Schapke, S.-E. 2011. A Distributed Multi-Model-Based Management Information System for Simulation and DecisionMaking on construction projects, Advanced Engineering Informatics 25(4): 582-599.

Schreyer, M.; Bögl, M.; Benning, P. 2010. A Smart Decision Making Framework for Building Information Models, InPro Public Report of Deliverable iewD10, January 2010, Dortmund.

Tvaronavičienė, M. 2014. If industrial sector development is sustainable: Lithuania compared to the EU, Entrepreneurship and Sustainability Issues 1(3):134-142. DOI: http://dx.doi.org/10.9770/jesi.2014.1.3(2)

Tvaronavičienè, M.; Šimelytė, A., Lace, N. 2014. Sustainable development facets: exporting industrial sectors from inside, Journal of Security and Sustainability Issues 3(4): 37-44. DOI: http://dx.doi.org/10.9770/jssi.2014.3.4(4)

Vasiliūnaitè, R. 2014. Sustainable development: methodological approaches toward issues, Journal of Security and Sustainability Issues 3(3): 69-75. DOI: http://dx.doi.org/10.9770/jssi.2014.3.3(6)

Vosylius, E.; Rakutis, V.; Tvaronavičienè, M. 2013. Economic growth, sustainable development and energy security interrelation, Journal of Security and Sustainability Issues 2(3): 5-14. DOI: http://dx.doi.org/10.9770/jssi.2013.2.3(1)

Romy GURUZ, Graduate Student, Technische Universität Dresden, Civil Engineering, Germany.

Prof. Dr. Ing. Raimar Joseph SCHERER, Head of the Institute for Construction Informatics Department of Civil Engineering TU Dresden, Germany.

This is an open access journal and all published articles are licensed under a $\underline{\text { Creative Commons Attribution 4.0 International License }}$ 